\title{
NUMERICAL SIMULATION OF BLASTING DUST POLLUTION IN OPEN-PIT MINES
}

\author{
HUANG, Z. ${ }^{1,2^{*}}-$ GE, S. ${ }^{1,2,3}-$ JING, D. ${ }^{1,2}-$ YANG, L. ${ }^{1,2}$ \\ ${ }^{1}$ College of Safety Science and Engineering, Liaoning Technical University, Fuxin 123000, \\ China \\ ${ }^{2}$ Key Laboratory of Mine Thermodynamic Disasters and Control of Ministry of Education, \\ Fuxin 123000, China \\ ${ }^{3}$ Taiyuan University of Technology, Taiyuan 030024, China \\ *Corresponding author \\ e-mail: huangzhihui666@sina.com
}

(Received $27^{\text {th }}$ Sep 2018; accepted $16^{\text {th }}$ Jul 2019)

\begin{abstract}
To solve the problem of dust pollution caused by bench blasting in open-pit mines and to solve the current situation of blasting dust control efficiency in most open-pit mines, the blasting dust removal mechanism and migration law were studied in this paper. In this paper, taking the bench blasting in Fushun China open-pit mines as an example, a real-time simulation of blasting dust pollution in open-pit mines was conducted through the numerical simulation by Fluent software and field test using the theories of gas-solid two-phase flow and explosion mechanics. The results showed that in the stage of impact movement and mushroom cloud formation, the explosive gas produced by blasting expanded rapidly, and a large amount of dust rushed into the atmospheric space under the effect of blasting impact kinetic energy, and then diffused. The migration velocity of dust was very lowly without wind. The dust with a particle size of 60-100 $\mu \mathrm{m}$ settled slowly, and the dust with a particle size of below $40 \mu \mathrm{m}$ settled with difficulty due to the strong disturbance by air flow. Based on the law of dust pollution, this paper provides a basis for the design of reasonable parameters of dustproof net and related parameters of remote mist emitter, and provides a theoretical and practical basis for the control of blasting dust in other open pit mines.
\end{abstract}

Keywords: blasting dust, dust migration law, numerical simulation, gas-solid two-phase flow, strip mine

\section{Introduction}

With the continuous expansion of production scale of open-pit mines, the problem of blasting dust pollution is becoming more and more serious. Blasting is mainly a process of rapid expansion of explosive gas with huge energy, in which a large amount of dust rushes into the atmospheric space under the effect of blasting impact kinetic energy, and then diffuses. The dust expands rapidly at the beginning of blasting, then gradually slows down, and finally tends to be stable. The dust of large particle size settles slowly, and most of the dust of small particle size diffuses slowly with the explosive gas (Jing et al., 2007; Ghose and Majee, 2001; Yang et al., 1996; Chen et al., 2013).

The local blasting dust concentration reached thousands of milligrams per cubic meter. Therefore, it not only endangers the health of workers, affects the normal operation of nearby production equipment, but also may endanger the health of surrounding residents (Baxter and Smith, 1993). A lot of studies have been done on explosive dust, for example, Jiang (2007) conducted real-time simulation of dust diffusion motion shape based on coal dust particle system, and developed BSMS simulation software. Their research has a lot of advantages, but due to the limitations of 
computer performance at that time, they failed to simulate the law of blasting dust pollution more visually. On the basis of summarizing the predecessors, in this paper, taking the bench blasting in Fushun China open-pit mines as an example, a reasonable simplification was conducted according to the actual conditions of blasting site, and a corresponding mathematical model was established, and the movement track of dust particles was tracked by Fluent software (Fu and Liu, 2017; Shen et al., 2017; Lenart, 2017), and the simulation results were analyzed, and simple and effective dust control measures were taken, finally, the dust control measures were tested through the numerical simulation and field test of dust (Zhang et al., 2018; Nongqwenga and Modi, 2017; Peng et al., 2018; Wang et al., 2018; Wu, 2016). By analyzing the law of dust pollution, the reasonable proportion of water stemming and solid stemming and the reasonable height of dust screen are calculated.

\section{General situation of blasting dust pollution and determination of basic characteristics of dust in east open pit mine in Fushun, China}

\section{Description of the diffusion process of dust}

Fushun China East Open-pit Mine is located in the northern temperate zone. It is located in the east longitude $99^{\circ}$ north latitude $47^{\circ}$. The pit is $5.7 \mathrm{~km}$ long from east to west, $1.9 \mathrm{~km}$ wide from north to south, and covers an area of $9.2 \mathrm{~km}^{2}$. The deep-hole loosening blasting was adopted in 32\# station working face, and the blasting parameters are shown in Table 1. The blasting pile did not form an obvious blasting funnel in the original place after blasting, and the degree of crushing of blasting body can meet the requirements of subsequent collision transportation, improve working efficiency and service life of equipment.

Through the observation and data analysis on the blasting site of East Open-pit Mine, it was found that in the process of open-pit blasting, the blasting dust rushed into the atmospheric space after leaving the blasting body under the effect of blasting impact kinetic energy (Yang et al., 2018; Zamora Figueroa et al., 2017; Jiang et al., 2017). Dust movement in the atmosphere can be roughly divided into three stages: (1) impact movement stage; (2) mushroom cloud formation stage; (3) diffusion stage. In this stage, the dust particles generated and excited by blasting vary greatly in the movement state. Although it lasted a short time, the dust concentration was high, as the local blasting dust concentration reached thousands of milligrams per cubic meter, as shown in Figure 1.

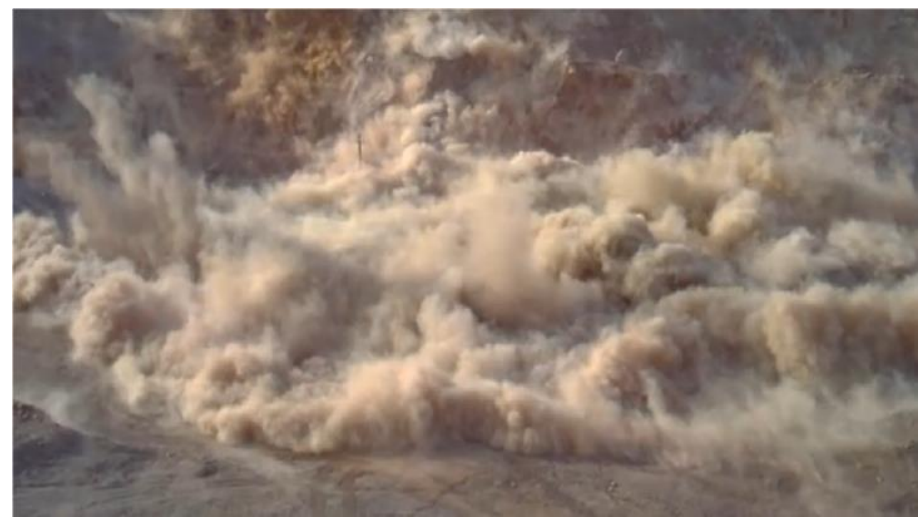

Figure 1. Blowing dust after blasting 
Table 1. Blasting mesh parameters (unit: $m$ )

\begin{tabular}{c|c|c|c}
\hline Aperture & $\mathbf{0 . 1 5 5} \mathbf{~ m}$ & Bench blasting & $\mathbf{7 ~ m}$ \\
\hline Borehole row spacing & $4 \mathrm{~m}$ & Super depth & $1-2 \mathrm{~m}$ \\
Borehole column spacing & $6 \mathrm{~m}$ & Packing length & $3 \mathrm{~m}$ \\
Borehole depth & $7-8 \mathrm{~m}$ & Burden & $4.5 \mathrm{~m}$ \\
\hline
\end{tabular}

\section{Materials and methods for testing the physical properties of dust}

(1) Sampling requirements for testing the basic characteristics of dust

1) Sampling site for testing the basic characteristics of dust

a. Determination of dust concentration: the damage of dust to human body is determined by the concentration of free silica. Generally, the suspended dust $1.5 \mathrm{~m}$ above the ground (respiratory zone height) was determined;

b. Determination of dust dispersion: the dispersion of dust usually refers to a collection of percentages of particles with different particle sizes. Generally, the dust of different concentrations at different places were collected for many times.

2) The basic characteristics of dust in working face should be tested by taking into account the influence of air humidity, temperature, wind speed and so on. The following points should be considered in selecting the right time to test it:

a. The dust concentration was determined at the same place and the same wind speed.

b. The change value of dust concentration was determined at different times after blasting and the same wind speed.

In the course of testing the basic characteristics of dust, the following test instruments were used: AH-91A Dust Sampler produced in Wuxi (depending on the actual situation); glass fiber filters produced by Sephorlebo ( $\Phi 75 \mathrm{~mm}$ if the dust concentration was greater than $200 \mathrm{mg} / \mathrm{m}^{3} ; \Phi 40 \mathrm{~mm}$ if the dust concentration was less than $200 \mathrm{mg} / \mathrm{m}^{3}$ ); scales, tweezers, drying boxes, etc.

\section{(2) Detection contents of dust dispersion}

To deeply reveal the influence of dust on human body and equipment, and to design a more simple and effective dust removal scheme, we introduced the dispersion test.

\section{1) Detection methods and specific contents}

It was mainly detected by quantity and quality dispersion, and the observation method by microscope was most commonly used for the quantity dispersion. The dust sample was made into a standard sheet, tested by a microscope, and the content was calculated, and the dispersion was finally determined. Equation 1 was used to calculate it:

$$
P_{n_{i}}=\left(n_{i} / \sum n_{i}\right) \times 100 \%
$$

where: $\mathrm{P}_{\mathrm{ni}}$-Particle size dispersion; $\mathrm{n}_{\mathrm{i}}$ - The sum of the number of dust particles of specified particle size, pcs; $\Sigma n_{i}$ - The sum of the number of dust particles of different particle sizes, pcs. 
Weight dispersion: within a given range, the ratio of the sum of the mass of dust particles contained in each particle size interval to the sum of the mass of total dust particles was usually expressed as a percentage. Equation 2 was used to calculate it:

$$
P_{w i}=\frac{w i}{\sum w i \times 100 \%}
$$

Where: wi-The sum of the mass of dust particles in a certain particle size range; Pwi-The percentage of the mass of dust particles in a certain particle size range, $\%$.

\section{2) Main test instruments}

Perchloroethylene fiber filter membrane; butyl acetate solvent; glass slide; microscope; computer microimage processing system; etc.

\section{Determination results of dust}

Because of the particularity and danger of determination of dust, it was necessary to use advanced testing instruments and means to test the concentration and dispersion and other important parameters of dust in a comprehensive and systematic way, which provided an important basis for selecting suitable dust control schemes. The test results are shown in Tables 2 and 3. Dust particles are irregular in shape and the equivalent diameter of the dust is usually used to describe the size of the dust particles. Dust particles vary and the particle size of dust is in accordance with Rosin-Rammler distribution after experimental analysis. Figure 2 is drawn from the test dust sampling results, and the median particle size value is the particle diameter $\bar{d}=170$ when $\mathrm{Y}_{\mathrm{d}}=0.368$.

Table 2. Dust concentration of 32\# station working face on the blasting site

\begin{tabular}{c|c|c|c|c}
\hline Test number & Test site & $\begin{array}{c}\text { Dust concentration } \\
\mathbf{m g} / \mathbf{m}^{\mathbf{3}}\end{array}$ & Test time & Test condition \\
\hline 1 & 306.7 & 10 & 60 S after blasting, no wind \\
2 & $\begin{array}{c}\text { Station working face } \\
\text { on the blasting site }\end{array}$ & 273.5 & 10 & 60 S after blasting, no wind \\
3 & 311.2 & 10 & 60S after blasting, no wind \\
\hline
\end{tabular}

Table 3. Dust dispersion of 32\# station working face on the blasting site

\begin{tabular}{c|c|c|c|c|c|c|c}
\hline \multirow{2}{*}{ Test number } & \multirow{2}{*}{ Test site } & \multirow{2}{*}{ Test time } & \multicolumn{5}{|c}{ Mass dispersion \% (mean) } \\
\cline { 4 - 8 } & & & $<30$ & $\mathbf{3 0 - 9 0}$ & $\mathbf{9 0 - 1 5 0}$ & $\mathbf{1 5 0 - 2 7 0}$ & $>\mathbf{2 7 0}$ \\
\hline 11 & & 10 & 6 & 10 & 34 & 43 & 7 \\
22 & $\begin{array}{c}\text { Station working face } \\
\text { on the blasting site }\end{array}$ & 10 & 5 & 10 & 35 & 45 & 5 \\
33 & 10 & 4 & 10 & 36 & 47 & 3 \\
\hline
\end{tabular}




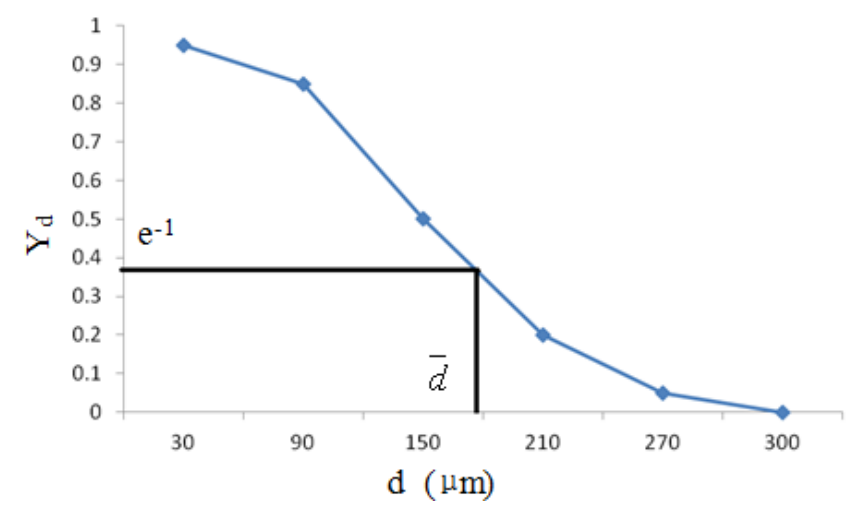

Figure 2. Size distribution of accumulate particle quality of total dust

\section{Establishment of mathematical model and determination of parameters}

According to the dust migration law, the discrete phase model of Euler-Lagrangian method was used to calculate the effect of turbulent velocity on particle motion by using random orbits.

\section{Mathematical model of continuous phase flow field}

\section{(1) Turbulence model}

It was generally recognized that the natural air flow was dominated by turbulent motion state, which thus directly affected the diffusion range of dust. It was necessary to briefly introduce the basic characteristics of turbulent motion.

Through a large number of tests, it can be concluded that: if the Reynolds number did not reach the critical value, we defined this flow as laminar flow (orderly flow between the flow layers); if the Reynolds number exceeded the critical value, we defined this flow as turbulence (chaotic and irregular flow of fluid). In the Cartesian coordinate system, the vector of velocity in the three coordinate axes (X-axis, Y-axis, Zaxis) was represented by $\mathrm{u}, \mathrm{v}$ and $\mathrm{w}$ respectively, and the governing Equations 3 and 4 can be expressed as:

$$
\begin{gathered}
\operatorname{div} \vec{u}=0 \\
\frac{\partial u}{\partial t}+\operatorname{div}(u \vec{u})=-\frac{1}{\rho} \frac{\partial p}{\partial x}+v \llbracket \operatorname{div}(\operatorname{grad} u) \\
\frac{\partial v}{\partial t}+\operatorname{div}(v \vec{u})=-\frac{1}{\rho} \frac{\partial p}{\partial y}+v \llbracket \operatorname{div}(\operatorname{grad} v) \\
\frac{\partial w}{\partial t}+\operatorname{div}(w \vec{u})=-\frac{1}{\rho} \frac{\partial p}{\partial z}+v \llbracket \operatorname{div}(\operatorname{grad} w)
\end{gathered}
$$

where: $\operatorname{grada}=\frac{\partial a}{\partial x}+\frac{\partial a}{\partial x}+\frac{\partial a}{\partial x} ; \mathrm{V}-\mathrm{Kinematic}$ viscosity coefficient, $\mathrm{m}^{2} / \mathrm{s} ; \mathrm{p}$-Pressure on a fluid microelement, pa. 
The pulsation can be taken into account by using the Reynolds averaging method, that is, the time average of the variable $\phi$ can be expressed as Equation 5:

$$
\bar{\phi}=\frac{1}{\Delta \mathrm{t}} \int_{t}^{t+\Delta t} \phi(t) d t
$$

where: “-"-Time average; $\phi$-Instantaneous value; $\bar{\phi}$-Time average; $\phi$ ' Pulsation value. $\phi, \bar{\phi}, \phi^{\prime}$-The three were as Equation 6:

$$
\phi=\bar{\phi}+\phi^{\prime}
$$

If the instantaneous value was replaced by the sum of the time average and pulsation value that is following as Equation 7:

$$
u=\bar{u}+u^{\prime} \quad v=\bar{v}+v^{\prime} \quad w=\bar{w}+w^{\prime} \quad p=\bar{p}+p^{\prime}
$$

By substituting the Equation 7 in the Equation 3, Equation 4, the following formulas can be obtained:

1) Continuity equation (Almstedt, 2003)

Continuity equation is as Equation 8.

$$
\frac{\partial}{\partial x_{i}}\left(\rho u_{i}\right)=0
$$

where: $\rho$-Gas density, $\mathrm{km} / \mathrm{m}^{3} ; \mathrm{u}_{\mathrm{i}}$ - Gas velocity vector.

2) Momentum equation ( $\mathrm{N}-\mathrm{S}$ equation)

Momentum equation is as Equation 9.

$$
\frac{\partial}{\partial x_{j}}\left(\rho u_{i} u_{j}\right)=-\frac{\partial}{\partial x_{j}}\left(\mu \frac{\partial u_{i}}{\partial x_{j}}-\rho \overline{u_{i}^{\prime} u_{j}^{\prime}}\right)
$$

where: $\mathrm{xi}$ - Coordinates in the $\mathrm{x}, \mathrm{y}, \mathrm{z}$ direction, $\mathrm{m}$; ui-The velocity of gas in the $\mathrm{x}, \mathrm{y}$, $\mathrm{z}$ direction, $\mathrm{m} / \mathrm{s} ; \mathrm{p}$-Effective turbulent pressure, $\mathrm{Pa} ; \mu$-Dynamic viscosity coefficient $\mathrm{Pa} \bullet \mathrm{s}$.

\section{(2) Standard $k-\varepsilon$ equation model}

The standard k- $\varepsilon$ equation model was first introduced by Launder and Spalding in the late last century. Up to now, it is also very popular in the field of turbulence simulation. The turbulent dissipation rate $\varepsilon$ can be expressed by Equation 10:

$$
\varepsilon=\frac{\mu}{\rho} \overline{\left(\frac{\partial u_{i}^{\prime}}{\partial x_{k}}\right)\left(\frac{\partial u_{i}^{\prime}}{\partial x_{k}}\right)}
$$


The turbulent viscosity coefficient $\mu_{t}$ was a function of $\mathrm{k}$ and $\varepsilon$, that is, Equation 11:

$$
\mu_{t}=\rho C_{\mu} \frac{k^{2}}{\varepsilon}
$$

where: $\rho$ - Gas density, $\mathrm{kg} / \mathrm{m}^{3} ; \mathrm{C}_{\mu}$-Empirical constant; $\mathrm{k}$-Turbulence kinetic energy, $\mathrm{m}^{2} / \mathrm{s}^{2} ; \varepsilon-$ Turbulent kinetic energy dissipation rate, $\mathrm{m}^{2} / \mathrm{s}^{3}$.

In the standard $\mathrm{k}-\varepsilon$ model, $\mathrm{k}$ and $\varepsilon$ were two fundamental unknown quantities, and the corresponding transport equations were Equations 12 and 13:

$$
\begin{gathered}
\frac{\partial\left(\rho \varepsilon u_{i}\right)}{\partial x_{j}}=\frac{\partial}{\partial x_{j}}\left[\left(\mu+\frac{\mu_{t}}{\sigma_{k}}\right) \frac{\partial k}{\partial x_{j}}\right]+G_{k}+G_{b}-\rho \varepsilon-Y_{M}+S_{k} \\
\frac{\partial\left(\rho \varepsilon u_{i}\right)}{\partial x_{j}}=\frac{\partial}{\partial x_{j}}\left[\left(\mu+\frac{\mu_{t}}{\sigma_{\varepsilon}}\right) \frac{\partial \varepsilon}{\partial x_{j}}\right]+G_{1 \varepsilon} \frac{\varepsilon}{k}\left(G_{K}+G_{3 \varepsilon} G_{b}\right)-G_{2 \varepsilon} \rho \frac{\varepsilon^{2}}{k}+S_{\varepsilon}
\end{gathered}
$$

where: $\mathrm{G}_{\mathrm{k}}$ - he generating term of turbulent kinetic energy caused by average velocity gradient; $\mathrm{G}_{\mathrm{b}}$ - Turbulent kinetic energy caused by buoyancy; $\mathrm{Y}_{\mathrm{M}}$ - Contribution of pulsation expansion in compressible turbulence; $G_{1 \varepsilon}, G_{2 \varepsilon}, G_{3 \varepsilon}$-Empirical constants; $\sigma_{k}, \sigma_{\varepsilon}$ - The Prandtl number corresponding to the turbulent kinetic energy $\mathrm{k}$ and dissipation rate $\varepsilon ; S_{k}, S_{\varepsilon}$-User-defined source item.

When the fluid was steady-state incompressible, regardless of user-defined source item, $G_{b}=0, G_{3 \varepsilon}=0, Y_{M}=0, S_{k}=0, S_{\varepsilon}=0$, then the standard k- $\varepsilon$ model were Equations 14 and 15:

$$
\begin{gathered}
\frac{\partial\left(\rho \varepsilon u_{i}\right)}{\partial x_{j}}=\frac{\partial}{\partial x_{j}}\left[\left(\mu+\frac{\mu_{t}}{\sigma_{k}}\right) \frac{\partial k}{\partial x_{j}}\right]+G_{k}-\rho \varepsilon \\
\frac{\partial\left(\rho \varepsilon u_{i}\right)}{\partial x_{j}}=\frac{\partial}{\partial x_{j}}\left[\left(\mu+\frac{\mu_{t}}{\sigma_{\varepsilon}}\right) \frac{\partial \varepsilon}{\partial x_{j}}\right]+G_{1 \varepsilon} \frac{\varepsilon}{k} G_{k}-G_{2 \varepsilon} \rho \frac{\varepsilon^{2}}{k}
\end{gathered}
$$

where: $G_{k}=\mu_{t} \frac{\partial u_{i}}{\partial x_{j}}\left(\frac{\partial u_{i}}{\partial x_{j}}+\frac{\partial u_{j}}{\partial x_{i}}\right)$.

By deriving from experimental data and theoretical derivation, $G_{1 \varepsilon}=1.44$, $G_{2 \varepsilon}=1.92, \sigma_{k}=1.0, \sigma_{\varepsilon}=1.3$ were obtained.

The discrete phase model of Euler-Lagrangian method was adopted according to the dust migration law. 


\section{Mathematical model of discrete phase}

According to the force balance on the droplet (particle), the equation of motion of the particle in Lagrangian coordinate system can be obtained (O'Rourke, 1981; Jin, 2010; Guo, 2006; Luo and Shen, 2006) as Equations 16 and 17:

$$
\begin{gathered}
\frac{d u_{p}}{d t}=F_{D}\left(u-u_{p}\right)+g_{x}\left(\rho_{p}-\rho\right) / \rho_{p}+F_{x} \\
F_{D}=\frac{18 \mu}{\rho_{p} D_{p}^{2}} \frac{C_{D} \operatorname{Re}}{24}
\end{gathered}
$$

where: $\mathrm{u}-$ Continuous phase velocity, $\mathrm{m} / \mathrm{s} ; \mathrm{u}_{\mathrm{p}}-$ Particle velocity, $\mathrm{m} / \mathrm{s} ; \mu-$ Molecular viscosity coefficient of the fluid, $\mathrm{Pa} \bullet \mathrm{s} ; \rho, \rho_{p}$ - The density of the fluid and the particle respectively; $\mathrm{kg} / \mathrm{m}^{3} ; D_{p}$ - Particle diameter, $\mathrm{m}$; Re was a relative Reynolds number, which was defined as Equation 18:

$$
\operatorname{Re}=\frac{\rho D_{p}\left|u_{p}-u\right|}{\mu}
$$

The resistance coefficient $C_{D}=\alpha_{1}+\frac{\alpha_{2}}{\mathrm{Re}}+\frac{\alpha_{3}}{\mathrm{Re}^{2}}, \alpha_{1}, \alpha_{2}, \alpha_{3}$ was a constant, which was given according to the experimental results of smooth spherical particles.

The other method for determining $C_{D}$ was Equation 19:

$$
C_{D}=\frac{24}{\operatorname{Re}}\left(1+b_{1} \operatorname{Re}^{b_{2}}\right)+\frac{b_{3} \operatorname{Re}}{b_{4}+\operatorname{Re}}
$$

The form factor was defined as $\varphi=s / S$, s was the surface area of the sphere of the same volume as the particle; $S$ was the actual surface area of the particle. Then the above constants were Equations 20-23:

$$
\begin{gathered}
b_{1}=2.3288-6.4581 \phi+2.4486 \phi^{2} \\
b_{2}=0.0964+0.5565 \phi \\
b_{3}=4.905-13.8944 \phi+18.4222 \phi^{2}-10.2599 \phi^{3} \\
b_{4}=1.4681+12.2584 \phi-20.7300 \phi^{2}+15.8855 \phi^{3}
\end{gathered}
$$

If the particle size was below micron, the Stokes resistance formula was used as Equation 24: 


$$
F_{D}=\frac{18 \mu}{D_{p}^{2} \rho_{p} C_{c}}
$$

where $C_{c}$ was the Cunningham correction coefficient, as Equation 25:

$$
C_{c}=1+\frac{2 \lambda}{D_{p}}\left[1.257+0.4 e^{\frac{1.1 D_{p}}{2 \lambda}}\right]
$$

where $\lambda$ was the mean molecular free path.

\section{Equation of motion of dust particle trajectory}

The equation of motion of dust particle trajectory can be solved step by step in discrete time step. The particle velocity at every position on the particle orbit can be obtained by integrating Equation 26.

$$
\frac{d_{x}}{d t}=u_{p}
$$

By solving the governing equations on each coordinate axis, the discrete phase dust particle trajectory can be obtained.

\section{Establishment of geometric model and generation of meshes}

(1) Overview of the establishment of geometric model

To simulate and analyze the practical problems, it was necessary to establish a similar model to approximate the practical engineering problems, so we established a geometric model according to the actual situation of the receiving station.

\section{(2) Division of meshes}

The meshes adopted in this paper are shown in Figure 3.
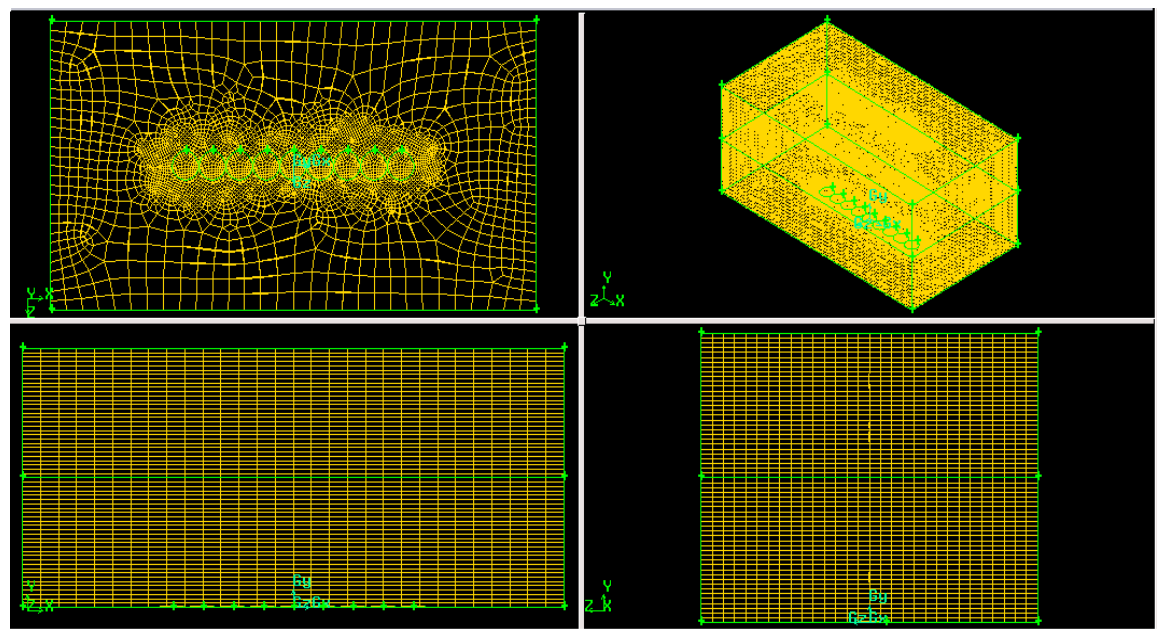

Figure 3. 3D mesh diagrams 


\section{Establishment of boundary conditions}

\section{(1) Establishment of continuous phase boundary conditions}

The boundary conditions, wall boundary conditions, and inlet and outlet boundary conditions involved in the simulation are shown in the Tables 4 and 5.

Table 4. Setting list of model

\begin{tabular}{c|c}
\hline Model & Define \\
\hline Solver & Segregated \\
& Implicit \\
Viscous model & Transient \\
Energy & $\mathrm{k}-\varepsilon$ \\
Discrete phase model & On \\
\end{tabular}

Table 5. Setting list of operating conditions

\begin{tabular}{c|c}
\hline Operating conditions & Setting \\
\hline Operating pressure (pa) & 101325 \\
& $\mathrm{X} 0$ \\
Gravitational acceleration & $\mathrm{Y} 0$ \\
& $\mathrm{Z}-9.8$ \\
Air density $\mathrm{kg} / \mathrm{m}^{3}$ & 1.225 \\
Air viscosity Pa॰s & 0.000018 \\
Dust density $\mathrm{kg} / \mathrm{m}^{3}$ & 1830 \\
Pressure-velocity & SIMPLEC \\
Pressure discretization & Standard \\
Discretization & Second order upwind \\
Convergence criterion & 0.001 \\
\hline
\end{tabular}

\section{(2) Establishment of discrete phase boundary conditions}

The assumption of mathematical model of dust movement was that when facing complex dust particles, we need to understand the main characteristics of dust, and we can ignore some subtle characteristics which have little influence on the calculation results, which can not only simplify the calculation, but also show the migration law of dust correctly. Therefore, we made the following assumptions, as shown in Table 6:

1) The dust particles were perceived as spheres

2) Initial velocity of dust ejection

3) The interaction between dust particles was neglected

4) The dust ejected steadily instantly

\section{Iterative calculation}

The unsteady numerical simulation by Fluent software according to the parameters and boundary conditions given above showed good convergence. The partial residual curve is shown in Figure 4. 
Table 6. Setting list of dust source parameters

\begin{tabular}{c|c}
\hline Injection & Define \\
\hline Injection type & Surface \\
Material & Fenchen \\
Diameter distribution & Rosin-Rammler \\
Min. diameter (m) & $1.0 \times 10^{-6}$ \\
Max. diameter (m) & $3.0 \times 10^{-4}$ \\
Mean diameter (m) & $1.7 \times 10^{-4}$ \\
Spread parameter & 2.42 \\
Total flow rate (kg/s) & 120 \\
Turbulent dispersion & Stochastic tracking \\
Number of tries & 500000 \\
Time scale constant & 0.16 \\
\hline
\end{tabular}

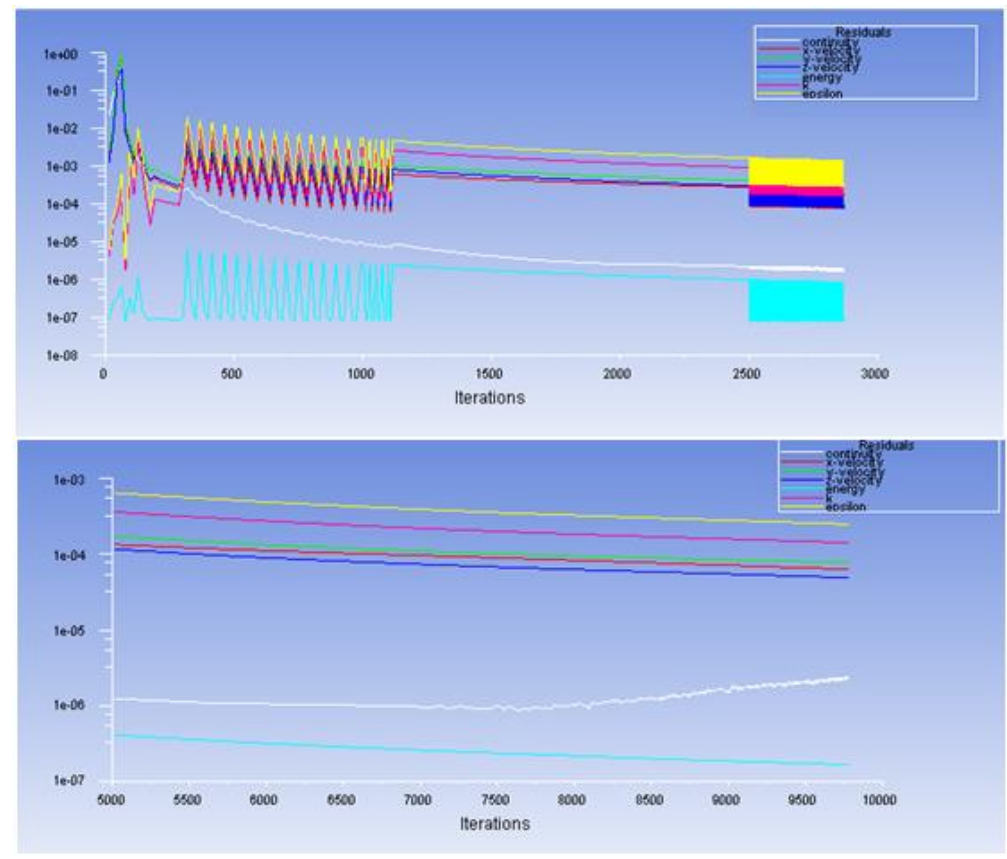

Figure 4. Partial residual curve diagram

\section{The analysis and discussion of the numerical simulation results of blasting blowing dust law}

To understand the movement state of dust more intuitively, a numerical simulation of the migration law of dust was conducted according to the field situation and relative conditions of blasthole arrangement (as shown in Figs. 5 and 6).

\section{Dust particle trajectory diagrams at different times after blasting}

The results showed that the change of the shape and migration velocity of dust was complex with the increase of time. 


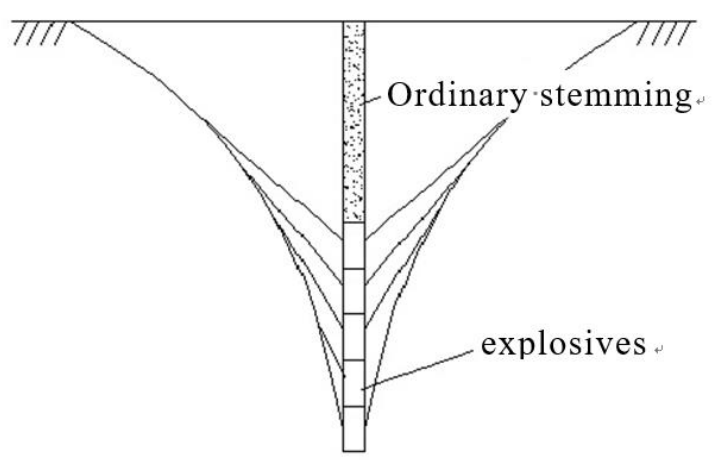

Figure 5. Deep-hole blasting stress curve diagram

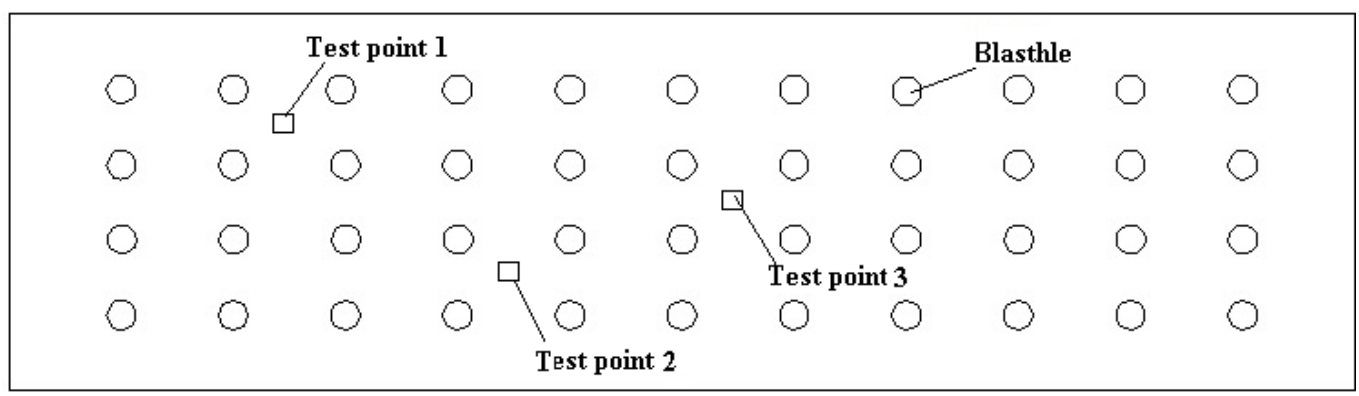

Figure 6. Blasthole arrangement and test point diagram

a. At the beginning of blasting, the initial velocity of dust was $50-65 \mathrm{~m} / \mathrm{s}$, and the average velocity of dust decreased to $30-40 \mathrm{~m} / \mathrm{s}$ after the 0.1 th second, and to $5-8 \mathrm{~m} / \mathrm{s}$ after $0.5 \mathrm{~s} \mathrm{(Fig.} \mathrm{7),} \mathrm{and} \mathrm{to} \mathrm{below} 3.5 \mathrm{~m} / \mathrm{s}$ after the 3 rd second (Fig. 8). In the stage of impact movement of dust, the impact force was strong, the velocity of dust varied greatly. The inertia of dust particles was greater than that of gas phase, and the inertia of dust of large particle size was greater than that of dust of small particle size. Therefore, the front end of blasting dust cloud was dust particles, which moved by inertia.

b. With the increase of time, the velocity of dust decreased gradually under the effect of air resistance, and the average velocity of dust decreased to 1.04-2.78 m/s at the 6 th second (Fig. 9), and was not obvious after the 6th second (Fig. 10), and became stable after this period of time. The heat carried by most of the explosive gases had basically been discharged into the atmosphere. Due to the release of huge blast energy, local pressure difference was produced, and a large amount of air came in because of the pressure difference, which slowly rose and diffused carrying dust.

c. The velocity of dust decreased to $0.6-1 \mathrm{~m} / \mathrm{s}$ after the 25 th second (Figs. 11 and 12) and varied slightly. Then, the diffusion stage began, and the range of dust pollution was also determined by this stage.

\section{Dust concentration diagrams at different times after blasting}

As can be seen from the dust concentration diagrams, the maximum dust concentration reached thousands of milligrams per cubic meter at the 0.1 th second. At the 3rd second (Fig. 13), the maximum dust concentration reached $1,660 \mathrm{mg} / \mathrm{m}^{3}$. The change of dust concentration in the inertial motion stage mainly depended on the change 
of the velocity of dust inertial motion (Fig. 14). At the 25th second (Fig. 15), the maximum dust concentration was $459 \mathrm{mg} / \mathrm{m}^{3}$, and the average dust concentration was $270 \mathrm{mg} / \mathrm{m}^{3}$. After $35 \mathrm{~s}$ of settlement (Fig. 16), the maximum dust concentration was $339 \mathrm{mg} / \mathrm{m}^{3}$, and the average dust concentration was $170 \mathrm{mg} / \mathrm{m}^{3}$. At this point, some of the dust of large particle size began to settle, and the change of dust concentration was determined by both the diffusion and settlement velocity of the dust. The change of dust concentration was very slow at later time points (Fig. 17).
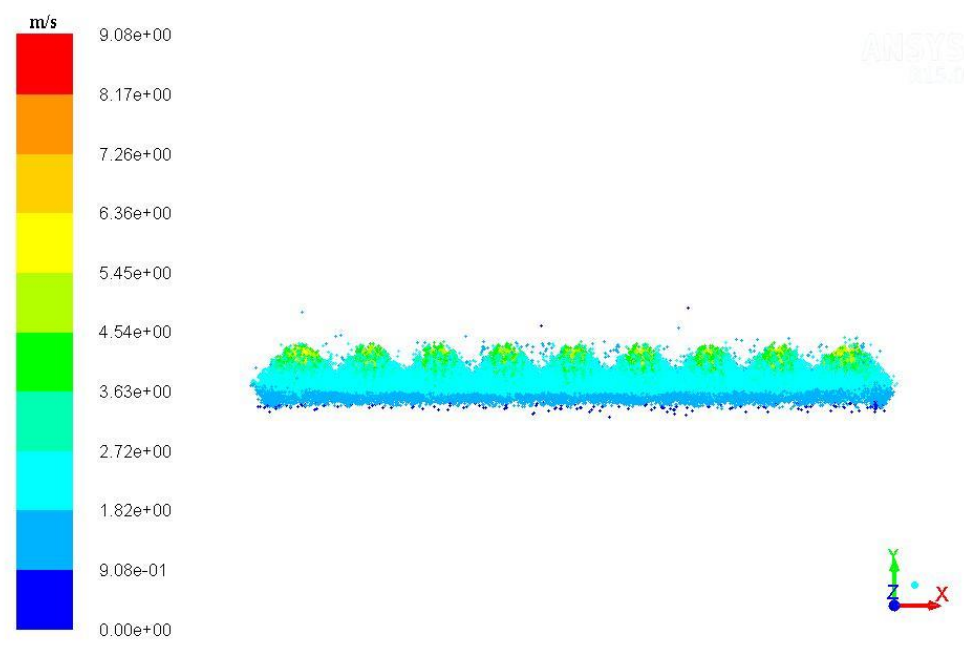

Figure 7. Dust particle trajectory diagram $(0.5 s)$
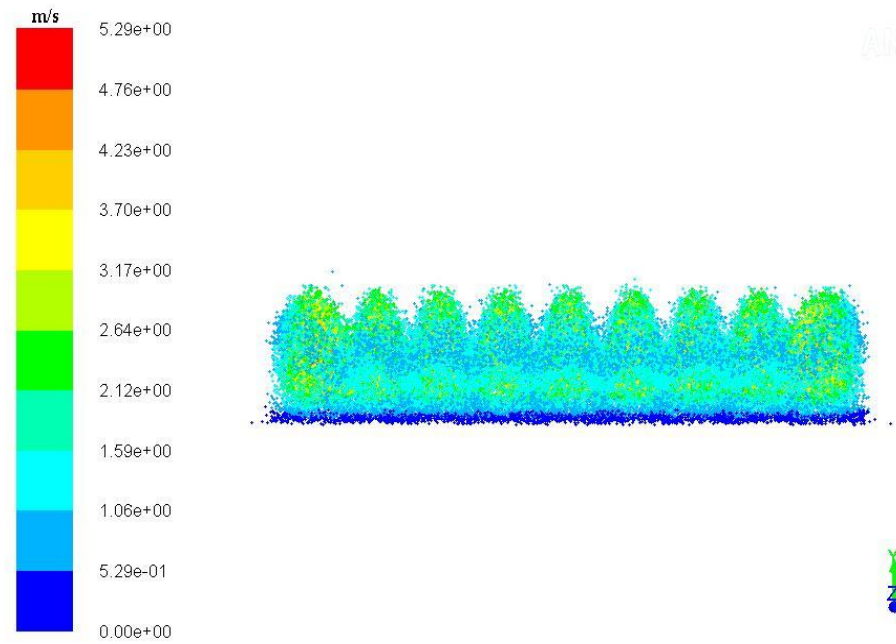

Figure 8. Dust particle trajectory diagram (3s)

\section{Dust particle size distribution diagrams at different heights at the same time after blasting}

In the process of numerical simulation of dust, a disk area was established every $5 \mathrm{~m}$ in the vertical direction. By capturing the dust particles passing through every plane, the probability distribution diagrams of the discrete amount of average diameter of dust at different vertical heights were obtained. Through the interpolation fitting by tecplot 
software, the probability distribution curve diagrams of dust particle size distribution at different heights were obtained. Through the analysis of each curve, it can be seen that at the 6th second (Fig. 18), the average diameter of the dust with a particle size of 200$300 \mu \mathrm{m}$ was about 5-10 m. After the 25th second (Figs. 19 and 20), the settling velocity of the dust with a particle size of greater than $250 \mu \mathrm{m}$ was very fast, and almost all of them had fallen to the ground. With the increase of vertical height of observation plane, the particle size of dust was becoming smaller and smaller, and the dust of large particle size can rapidly settle by its own gravity, but the dust of small particle size can suspend in the air for a long time under natural conditions. Due to the disturbance by air flow and the action of air resistance, the floating effect of the dust of large particle size decreased gradually. Some of the dust of large particle size settled by overcoming the buoyancy by its gravity, and the dust with a particle size of greater than $100 \mu \mathrm{m}$ began to settle at a fast settling velocity with the increase of settling time. Almost all the dust with a particle size of about $250 \mu \mathrm{m}$ fell to the ground after about $30 \mathrm{~s}$, the dust with a particle size of 60-100 $\mu \mathrm{m}$ settled slowly, and the dust with a particle size of below $40 \mu \mathrm{m}$ settled difficultly due to the strong disturbance by air flow.
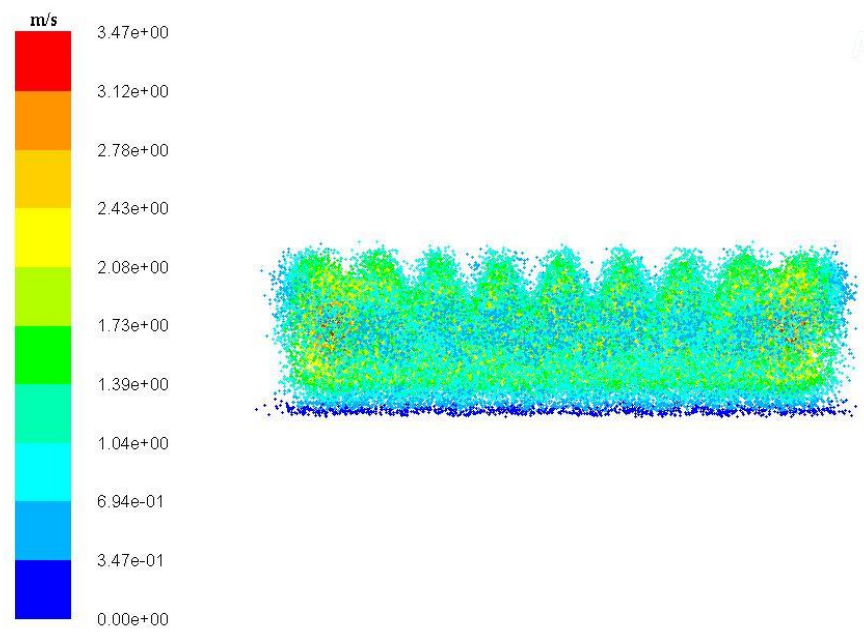

Figure 9. Dust particle trajectory diagram (6s)
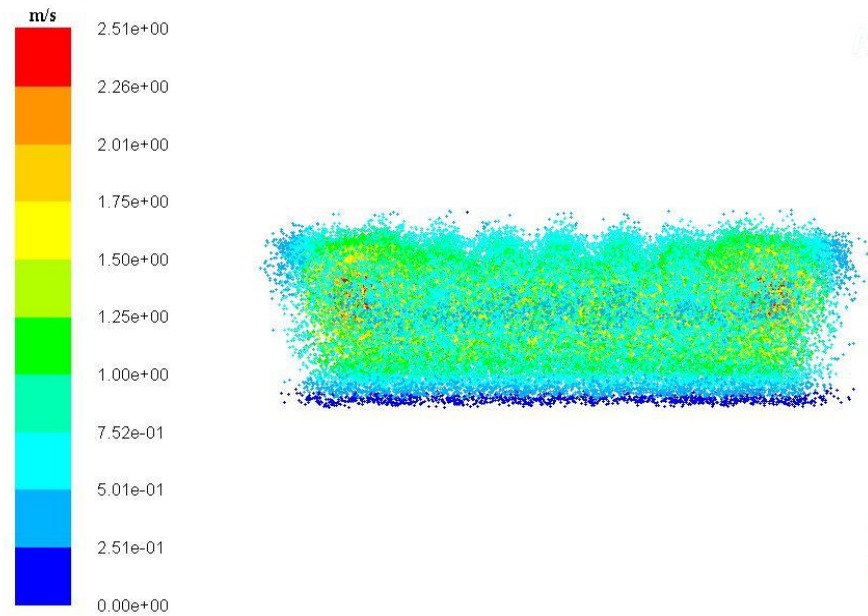

Figure 10. Dust particle trajectory diagram (10s) 

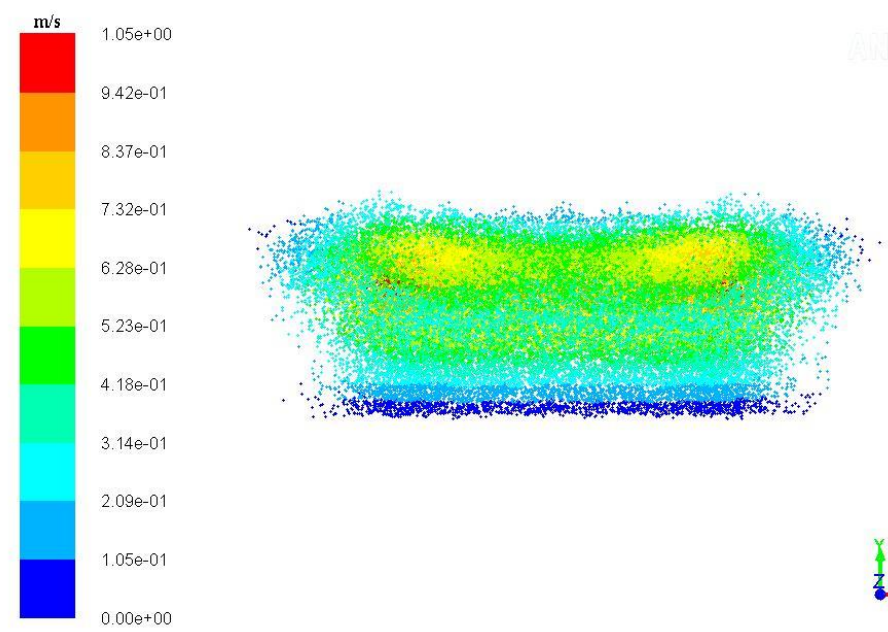

Figure 11. Dust particle trajectory diagram (25s)
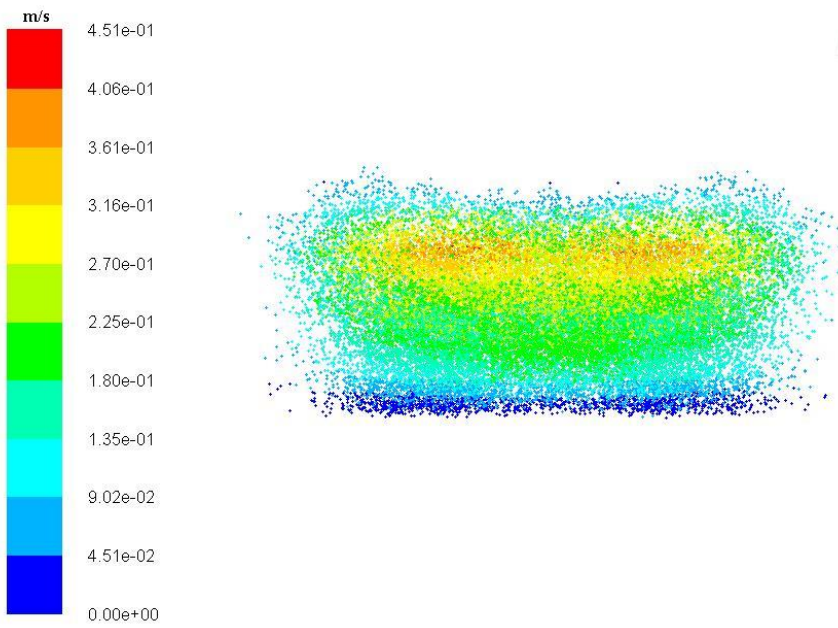

Figure 12. Dust particle trajectory diagram (60s)

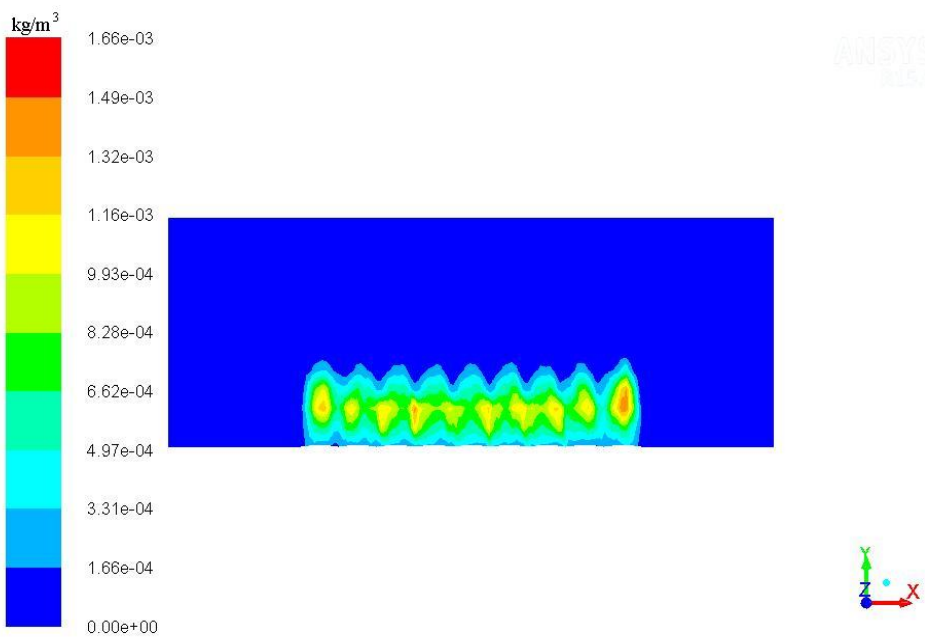

Figure 13. Dust concentration diagram (3s)

APPLIED ECOLOGY AND ENVIRONMENTAL RESEARCH 17(5):10313-10333. http://www.aloki.hu • ISSN 15891623 (Print) • ISSN 17850037 (Online) DOI: http://dx.doi.org/10.15666/aeer/1705_1031310333 (c) 2019, ALÖKI Kft., Budapest, Hungary 


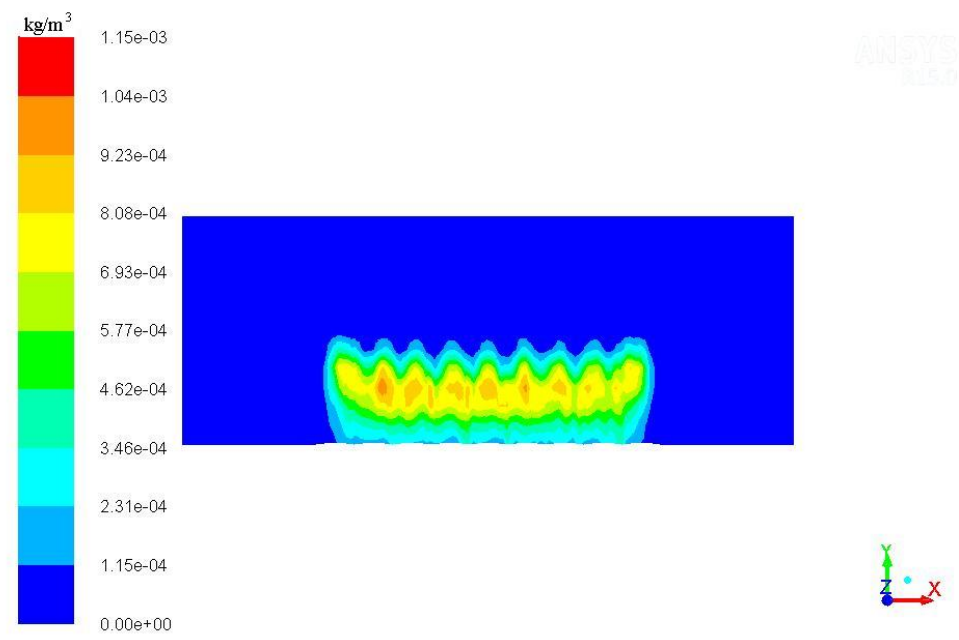

Figure 14. Dust concentration diagram (6s)
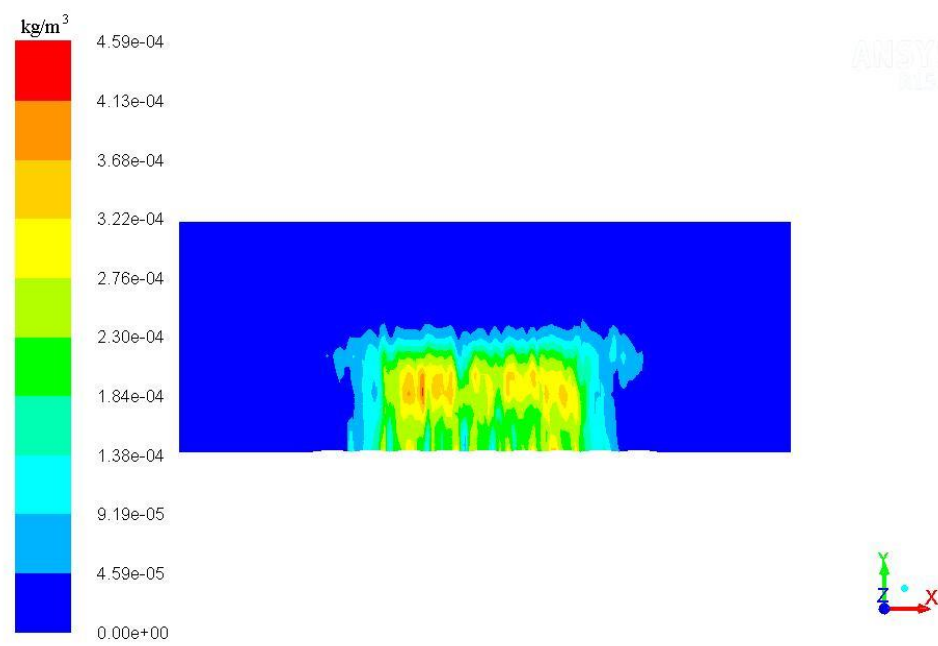

Figure 15. Dust concentration diagram (25s)

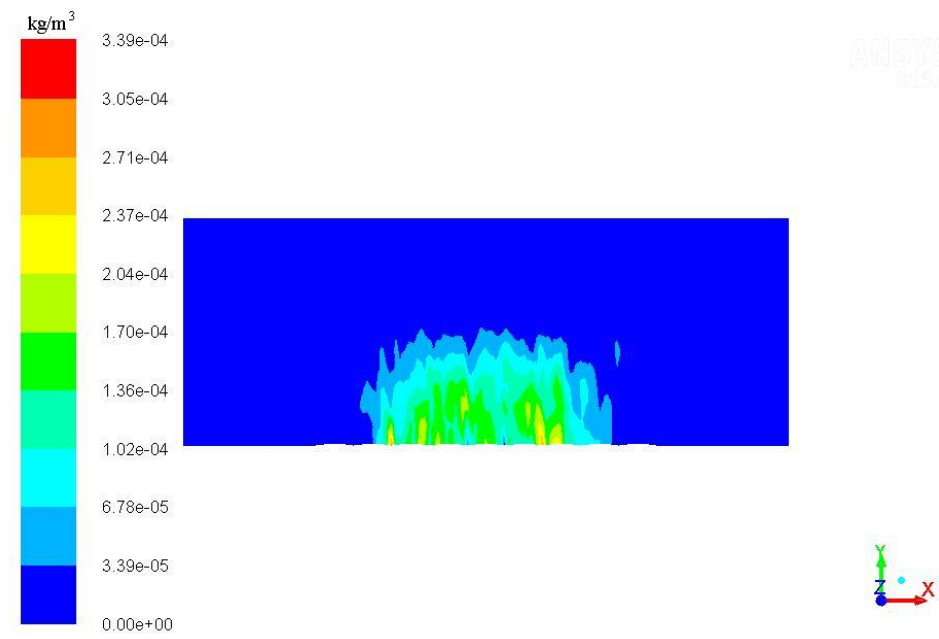

Figure 16. Dust concentration diagram (60s)

APPLIED ECOLOGY AND ENVIRONMENTAL RESEARCH 17(5):10313-10333. http://www.aloki.hu • ISSN 15891623 (Print) • ISSN 17850037 (Online) DOI: http://dx.doi.org/10.15666/aeer/1705_1031310333 (c) 2019, ALÖKI Kft., Budapest, Hungary 

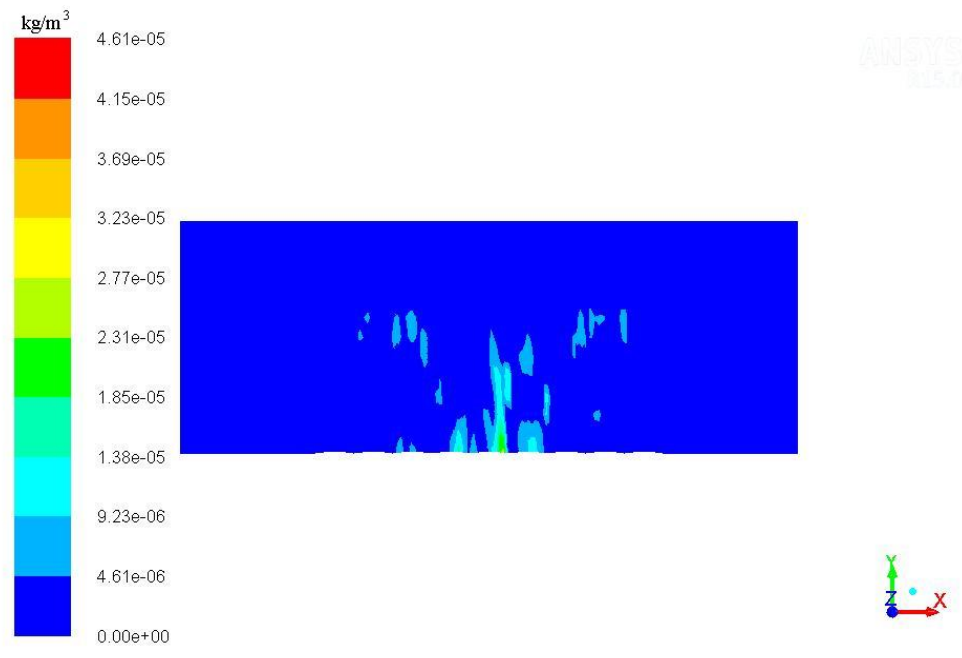

Figure 17. Dust concentration diagram (360 s)

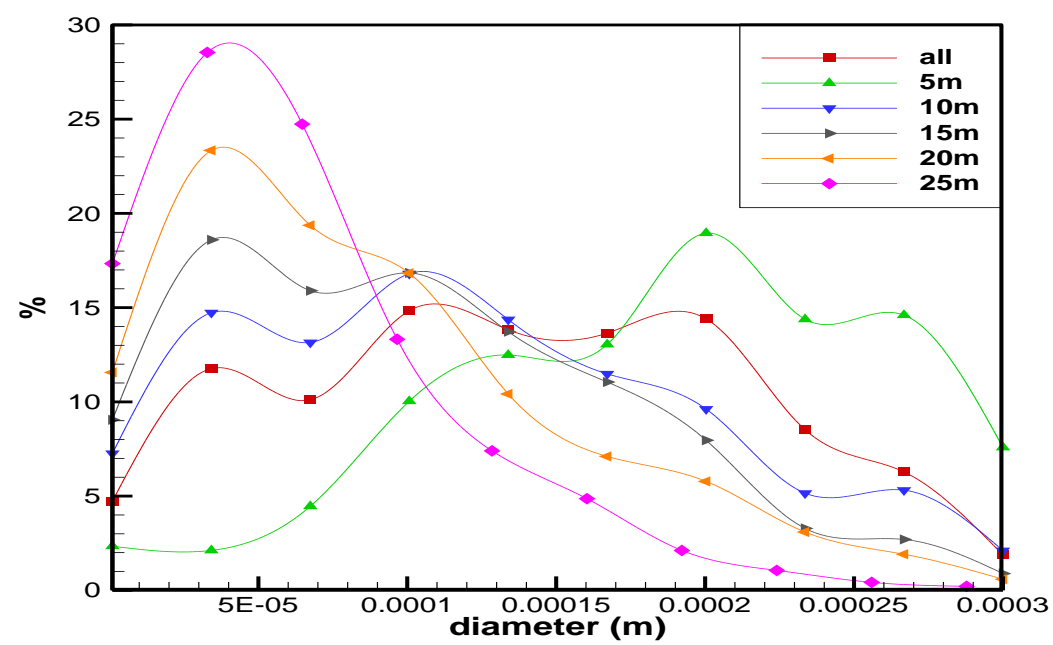

Figure 18. Probability distribution diagram of the discrete amount of average diameter ( $6 \mathrm{~s})$

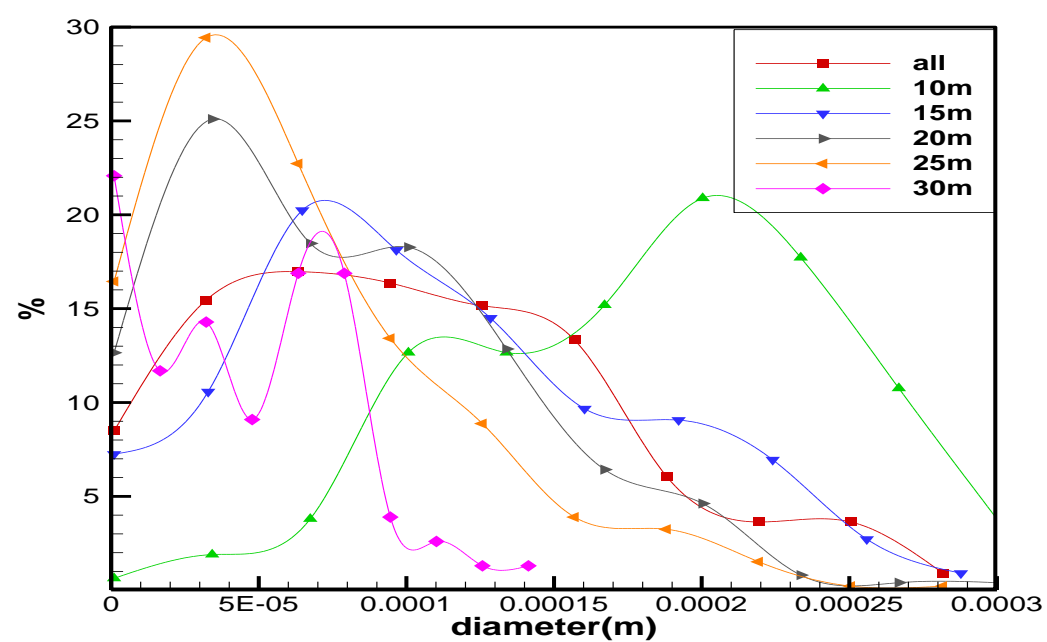

Figure 19. Probability distribution diagram of the discrete amount of average diameter $(25 \mathrm{~s})$ 


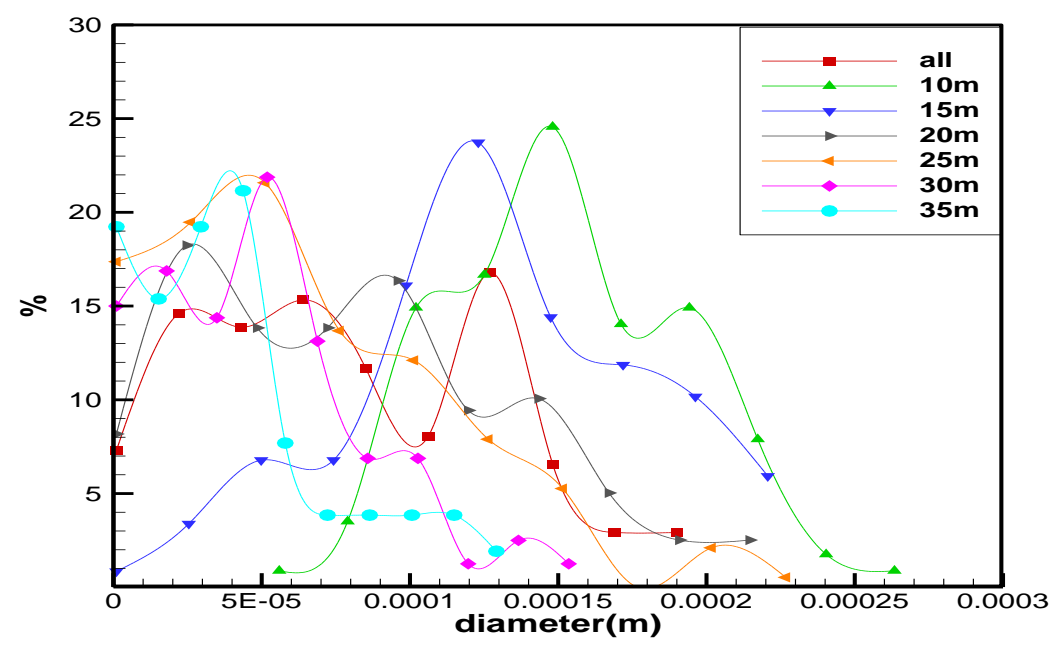

Figure 20. Probability distribution diagram of the discrete amount of average diameter (60 s)

\section{Result verification}

To verify the validity of the data, three test points were arranged at the blasting working face, and two direct reading dust testers were placed in each test point (the readings of the two testers were averaged). The dust concentration was measured at the 25th second (Fig. 21) and the 60th second (Fig. 22).

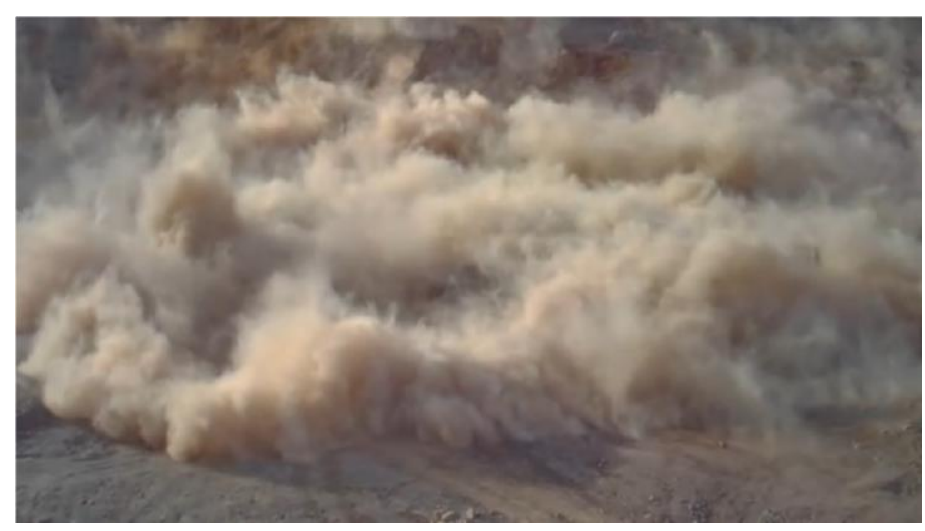

Figure 21. Blowing dust after blasting (25s)

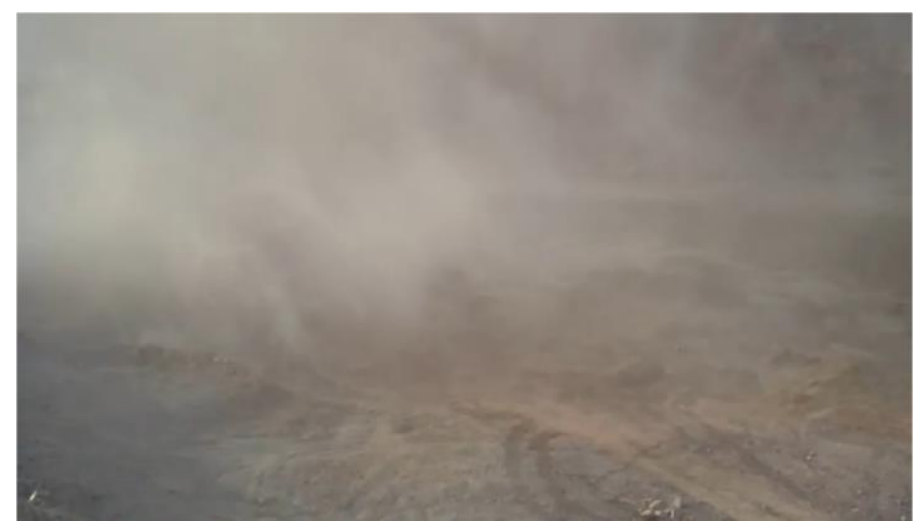

Figure 22. Blowing dust after blasting (60 s) 
The test results are shown in Tables 7 and 8 . In the $25 \mathrm{~s}$ after blasting, the average relative error of measured data and simulation data of three measuring points is $2.84 \%$, $2.69 \%$ and $3.01 \%$, both lower than $5 \%$, in the $60 \mathrm{~s}$ after blasting, the average relative error of measured data and simulation data of three measuring points is $3.26 \%, 2.59 \%$ and $2.39 \%$ respectively, the relative error of measured data and simulation data of the test point $1,2,3$ is under $5 \%$, all show relatively reliable numerical simulation results and the reasonable model, The model can be used in subsequent studies to test the difficult law of blasting dust and its influencing factors.

Table 7. Comparison of average dust concentration and simulated concentration in blasting working face (25s)

\begin{tabular}{c|c|c|c|c|c|c|c|c|c}
\hline \multirow{2}{*}{$\begin{array}{c}\text { Height perpendicular } \\
\text { to the ground }\end{array}$} & \multicolumn{3}{|c|}{ Measuring point 1 } & \multicolumn{3}{c|}{ Measuring point 2 } & \multicolumn{3}{c}{ Measuring point 3 } \\
\cline { 2 - 9 } & $\begin{array}{c}\text { Measuring } \\
\left(\mathbf{m g} / \mathbf{m}^{\mathbf{3}}\right)\end{array}$ & $\begin{array}{c}\text { Simulation } \\
\left(\mathbf{m g}_{\mathbf{m}}^{\mathbf{3}}\right)\end{array}$ & $\begin{array}{c}\text { Error } \\
\text { rate }\end{array}$ & $\begin{array}{c}\text { Measuring } \\
\left(\mathbf{m g} / \mathbf{m}^{\mathbf{3}}\right)\end{array}$ & $\begin{array}{c}\text { Simulation } \\
\left(\mathbf{m g} / \mathbf{m}^{\mathbf{3}}\right)\end{array}$ & $\begin{array}{c}\text { Error } \\
\text { rate }\end{array}$ & $\begin{array}{c}\text { Measuring } \\
\left(\mathbf{m g} / \mathbf{m}^{\mathbf{3}}\right)\end{array}$ & $\begin{array}{c}\text { Simulation } \\
\left(\mathbf{m g} / \mathbf{m}^{\mathbf{3}}\right)\end{array}$ & $\begin{array}{c}\text { Error } \\
\text { rate }\end{array}$ \\
\hline $5 \mathrm{~m}$ & 225 & 231 & $2.67 \%$ & 233 & 224 & $3.86 \%$ & 221 & 228 & $3.17 \%$ \\
$10 \mathrm{~m}$ & 168 & 162 & $3.57 \%$ & 171 & 165 & $3.51 \%$ & 174 & 169 & $2.87 \%$ \\
$15 \mathrm{~m}$ & 371 & 378 & $2.16 \%$ & 364 & 369 & $1.37 \%$ & 359 & 353 & $1.67 \%$ \\
$20 \mathrm{~m}$ & 439 & 432 & $1.59 \%$ & 428 & 433 & $1.17 \%$ & 437 & 428 & $2.06 \%$ \\
$25 \mathrm{~m}$ & 231 & 241 & $4.32 \%$ & 247 & 241 & $2.43 \%$ & 242 & 251 & $3.72 \%$ \\
$30 \mathrm{~m}$ & 146 & 150 & $2.73 \%$ & 158 & 152 & $3.80 \%$ & 152 & 159 & $4.61 \%$ \\
Average relative error & & & $2.84 \%$ & & & $2.69 \%$ & & & $3.01 \%$ \\
\hline
\end{tabular}

Table 8. Comparison of average dust concentration and simulated concentration in blasting working face $(60 \mathrm{~s})$

\begin{tabular}{c|c|c|c|c|c|c|c|c|c}
\hline \multirow{2}{*}{$\begin{array}{c}\text { Height perpendicular } \\
\text { to the ground }\end{array}$} & \multicolumn{3}{|c|}{ Measuring point 1 } & \multicolumn{3}{c|}{ Measuring point 2 } & \multicolumn{3}{c}{ Measuring point 3 } \\
\cline { 2 - 10 } & $\begin{array}{c}\text { Measuring } \\
\left(\mathbf{m g} / \mathbf{m}^{\mathbf{3}}\right)\end{array}$ & $\begin{array}{c}\text { Simulation } \\
\left(\mathbf{m g} / \mathbf{m}^{\mathbf{3}}\right)\end{array}$ & $\begin{array}{c}\text { Error } \\
\text { rate }\end{array}$ & $\begin{array}{c}\text { Measuring } \\
\left(\mathbf{m g} / \mathbf{m}^{\mathbf{3}}\right)\end{array}$ & $\begin{array}{c}\text { Simulation } \\
\left(\mathbf{m g} / \mathbf{m}^{\mathbf{3}}\right)\end{array}$ & $\begin{array}{c}\text { Error } \\
\text { rate }\end{array}$ & $\begin{array}{c}\text { Measuring } \\
\left(\mathbf{m g} / \mathbf{m}^{\mathbf{3}}\right)\end{array}$ & $\begin{array}{c}\text { Simulation } \\
\left(\mathbf{m g} / \mathbf{m}^{\mathbf{3}}\right)\end{array}$ & $\begin{array}{c}\text { Error } \\
\text { rate }\end{array}$ \\
\hline $5 \mathrm{~m}$ & 191 & 183 & $4.06 \%$ & 188 & 190 & $1.06 \%$ & 201 & 192 & $4.48 \%$ \\
$10 \mathrm{~m}$ & 181 & 187 & $3.31 \%$ & 173 & 179 & $3.47 \%$ & 185 & 176 & $4.86 \%$ \\
$15 \mathrm{~m}$ & 321 & 327 & $1.87 \%$ & 325 & 317 & $2.46 \%$ & 318 & 325 & $2.20 \%$ \\
$20 \mathrm{~m}$ & 174 & 167 & $4.02 \%$ & 169 & 164 & $2.96 \%$ & 177 & 172 & $2.82 \%$ \\
$25 \mathrm{~m}$ & 106 & 103 & $2.83 \%$ & 105 & 107 & $1.90 \%$ & 109 & 106 & $2.75 \%$ \\
$30 \mathrm{~m}$ & 85 & 82 & $3.52 \%$ & 82 & 79 & $3.66 \%$ & 78 & 80 & $2.56 \%$ \\
Average relative error & & & $3.26 \%$ & & & $2.59 \%$ & & & $2.39 \%$ \\
\hline
\end{tabular}

\section{Conclusions}

(1) In this paper, a real time simulation of blasting dust pollution in open-pit mines was conducted through the numerical simulation and field test of dust. In the stage of impact movement of dust, a large amount of dust rushed into the atmospheric space instead of settling under the effect of inertia.

(2) Almost all the dust with a particle size of about $250 \mu \mathrm{m}$ fell to the ground after about $30 \mathrm{~s}$, and the dust with a particle size of 60-100 $\mu \mathrm{m}$ settled slowly, and the dust with a particle size of below $40 \mu \mathrm{m}$ settled difficultly due to the strong disturbance by air flow.

Acknowledgements. Fund number 51704146, the project name Study on Dust Mesoscale Movement Characteristics and Dust Control Mechanism of Magnetized Spiral Pneumatic Mist Curtain in Fully Mechanized Heading Face Supported by National Natural Science Foundation of China. 


\section{REFERENCES}

[1] Almstedt, A. E. (2003): Methods for multiphase computational fluid dynamics. Chemical Engineering Journal 44(12): 39-152.

[2] Baxter, L. L., Smith, P. J. (1993): Turbulent dispersion of particles: the STP model. Enemy and Fuels 7: 852-859

[3] Chen J., Wang, Y., Jiang, Z. (2013): Numerical simulation of blasting dust concentration distribution and diffusion regularities in stope. - Journal of China Coal Society 38(z1): 147-152.

[4] Fu, H., Liu, X. A (2017): Study on the impact of environmental education on individuals' behaviors concerning recycled water reuse. - Eurasia Journal of Mathematics Science and Technology Education 13(10): 6715-6724.

[5] Ghose, M. K., Majee, S. R. (2001): Air pollution caused by opencast mining and its abatement measures in India. - Environ Manag 63(3): 193-199.

[6] Guo, Y. (2006): Discussion on the application of the water-stem in the blasting operation. - SCI-Tech Information Development and Economy 16(11): 280-281.

[7] Jiang, L., Tao, T., Zhang, C., Jiang, H., Wang, J. (2017): Summary of the port shoreline resource evaluation based on triangular fuzzy analytic hierarchy process. - Polish Maritime Research 24(SI): 16-22.

[8] Jin, L. (2010): Mine Dust Prevention and Control Theory. - Science Publishing Company, Bejing.

[9] Jing, Z. (2007): Simulated study of the blasting smog-dust movement on account of particle system. - Journal of University of Science and Technology Beijing 2: 25-29.

[10] Jing, Z., Wan, S., Sun, J. (2007): Simulated study of the blasting smog-dust movement on account of particle system. - Journal of University of Science and Technology Beijing 29(2): 25-29.

[11] Lenart, A. S. (2017): Sphere-to-spheroid comparison - numerical analysis. - Polish Maritime Research 24(4): 4-9.

[12] Luo, Y., Shen, Z. (2006): Influence of borehole stemming on blasting effect. Engineering Blasting 12(1): 16-18.

[13] Nongqwenga, N., Modi, A. T. (2017): Phosphorus and potassium quantity/intensity properties of selected South African soils (Kwazulu-Natal) and their correlation with selected soil parameters. - Applied Ecology and Environmental Research 15(3): 1-14.

[14] O'Rourke, P. J. (1981): Collective Droplets on Vaporizing Liquid Sprays. - University of Princeton, Princeton.

[15] Peng, W., Maleki, A., Rosen, M. A., Azarikhah, P. (2018): Optimization of a hybrid system for solar-wind-based water desalination by reverse osmosis: comparison of approaches. - Desalination 442: 16-31.

[16] Shen, Y., Zhao, N., Xia, M., Du, X. (2017): A deep q-learning network for ship stowage planning problem. - Polish Maritime Research 24(SI): 102-109.

[17] Wang, L., Wang, T., Liu, J., Wang, J. (2018): Correlation analysis of erectile dysfunction with lower urinary tract symptoms (LUTS) degree and clinical features in LUTS patients. - Iranian Journal of Public Health 47(5): 658-665.

[18] Yang, G., Li, H., Cheng, X. (1996): Mechanical analysis of blasting dust particles in movement. - Journal of Hebei Institute of Technology 18(4): 1-5.

[19] Yang, L., Yin, P., Li, K., Fan, H., Xue, Q., Li, X., Sun, L., Liu, Y. (2018): Seasonal dynamics of constitutive levels of phenolic components lead to alterations of antioxidant capacities in Acer truncatum leaves. - Arabian Journal of Chemistry 11(1): 14-25.

[20] Zamora Figueroa, A. C., Ramos Oropeza, J. R., Arias, M., Hernandez Valencia, I. (2017): Response of the microbial community to the biotreatment of a soil contaminated with a medium crude. - Revista Internacional De Contaminacion Ambiental 33(4): 629-639.

[21] Zhang, G., Li, L., Hao, C., Ren, J., Zhang, H., Jiao, J., Gao, L., Ding, S., Yao, S., Yao, W., Wu, W. (2016): Screening and preliminary verification of a phage display single- 
chain antibody library against coal workers' pneumoconiosis. - Journal of Occupational and Environmental Medicine 58(12): 1264-1269.

[22] Zhang, N., Zhou, C., Xia, W., Nguyen, A. V. (2018): Volatilization of mercury in coal during conventional and microwave drying and its potential guidance for environmental protection. - Journal of Cleaner Production 176: 1-6. 